\title{
Article
}

\section{Blood-based near-infrared spectroscopy for the rapid low-cost detection of Alzheimer's disease}

Paraskevaidi, Maria, Medeiros-De-morais, Camilo De lelis, Freitas, Daniel L. D., Lima, Kássio M. G., Mann, David M. A., Allsop, David, Martin-Hirsch, Pierre L. and Martin, Francis L

Available at http://clok.uclan.ac.uk/24202/

Paraskevaidi, Maria, Medeiros-De-morais, Camilo De lelis ORCID: 0000-00032573-787X, Freitas, Daniel L. D., Lima, Kássio M. G., Mann, David M. A., Allsop, David, Martin-Hirsch, Pierre L. and Martin, Francis L ORCID: 0000-0001-85624944 (2018) Blood-based near-infrared spectroscopy for the rapid low-cost detection of Alzheimer's disease. The Analyst, 24 (143). pp. 5959-5964. ISSN 0003-2654

It is advisable to refer to the publisher's version if you intend to cite from the work. http://dx.doi.org/10.1039/c8an01205a

For more information about UCLan's research in this area go to http://www.uclan.ac.uk/researchgroups/ and search for <name of research Group>.

For information about Research generally at UCLan please go to http://www.uclan.ac.uk/research/

All outputs in CLoK are protected by Intellectual Property Rights law, including Copyright law. Copyright, IPR and Moral Rights for the works on this site are retained by the individual authors and/or other copyright owners. Terms and conditions for use of this material are defined in the policies page.

\section{CLoK}

Central Lancashire online Knowledge www.clok.uclan.ac.uk

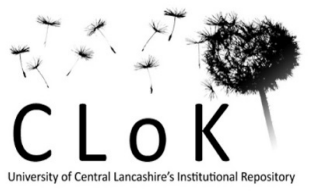




\section{Blood-based near-infrared spectroscopy for the rapid low-cost detection of}

2

3 Maria Paraskevaidi ${ }^{1, *}$, Camilo L. M. Morais ${ }^{1}$, Daniel L. D. Freitas ${ }^{2}$, Kássio M. G. Lima ${ }^{2}$, David

\section{Alzheimer's disease}

M. A. Mann ${ }^{3}$, David Allsop ${ }^{4}$ Pierre L. Martin-Hirsch ${ }^{5}$, Francis L. Martin 1,* 6 PRI 2HE, UK

$7 \quad{ }^{2}$ Institute of Chemistry, Biological Chemistry and Chemometrics, Federal University of Rio 8 Grande do Norte, Natal 59072-970, Brazil

$9 \quad{ }^{3}$ Clinical Neuroscience Research Group, Division of Medicine and Neuroscience, University 10 $11 U K$

$12{ }^{4}$ Division of Biomedical and Life Sciences, Faculty of Health and Medicine, Lancaster 13 University, Lancaster LA1 4YQ, UK

$14{ }^{5}$ Department of Obstetrics and Gynaecology, Central Lancashire Teaching Hospitals NHS 15

$29{ }^{1}$ To whom correspondence should be addressed. Email: mparaskevaidi@uclan.ac.uk or

16

17 18 19 30 of Manchester, Greater Manchester Neurosciences Centre, Hope Hospital, Salford M6 8HD, UK

\section{Foundation Trust, Preston PR2 9HT, UK}

(1)

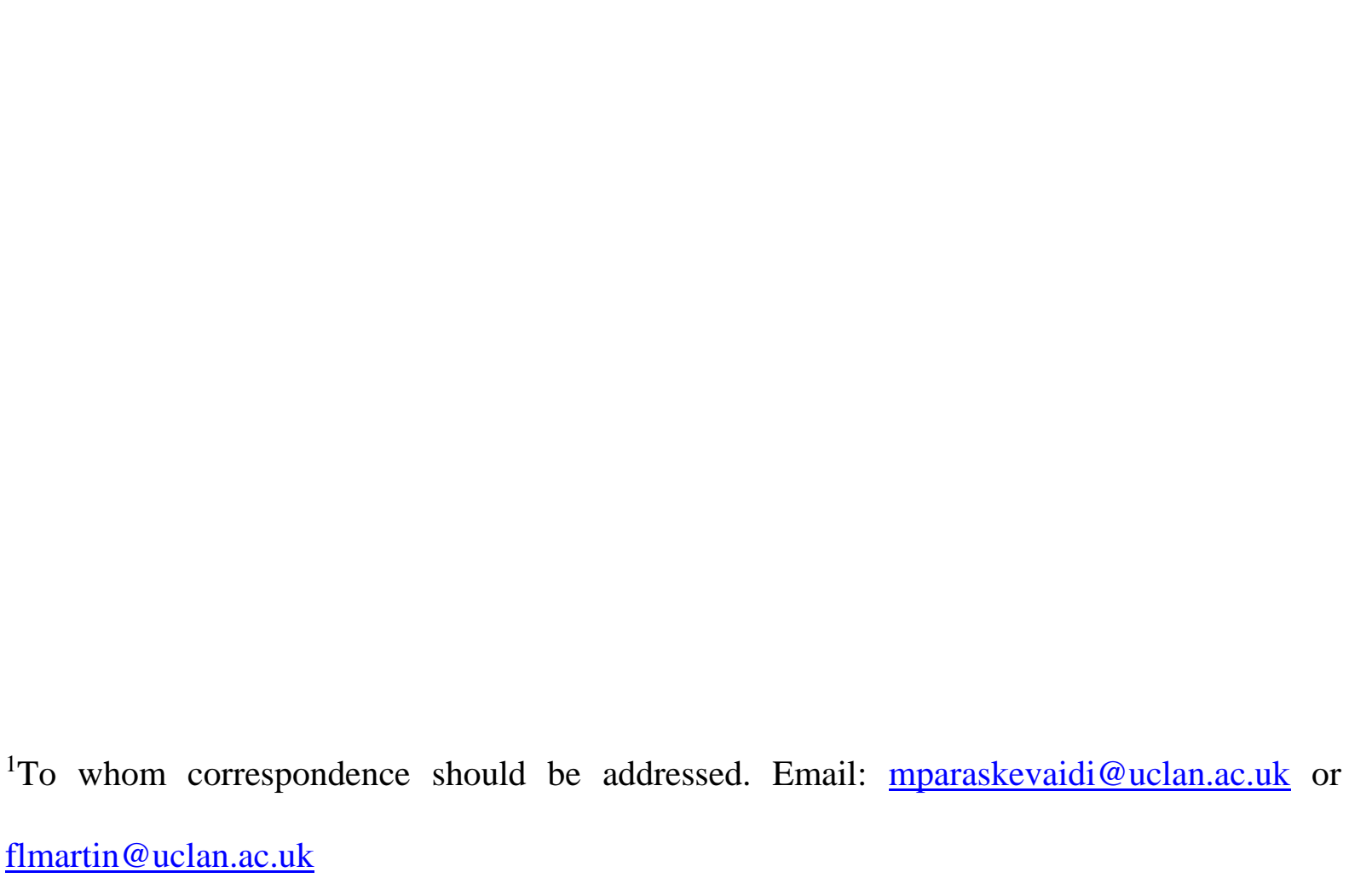


53 Keywords: Alzheimer's disease; multivariate classification; near infrared spectroscopy; PCA54

\section{Abstract}

Alzheimer's disease (AD) is currently under-diagnosed and is predicted to affect a great number of people in the future, due to the unrestrained aging of the population. An accurate diagnosis of $\mathrm{AD}$ at an early-stage, prior to (severe) symptomatology, is of crucial importance as it would allow the subscription of effective palliative care and/or enrolment into specific clinical trials. Today, new analytical methods and research initiatives are being developed for the on-time diagnosis of this devastating disorder. During the last decade, spectroscopic techniques have shown great promise in the robust diagnosis of various pathologies, including neurodegenerative diseases and dementia. In the current study, blood plasma samples were analysed with near-infrared (NIR) spectroscopy as a minimally-invasive method to distinguish patients with $\mathrm{AD}(n=111)$ from non-demented volunteers $(n=173)$. After applying multivariate classification models (principal component analysis with quadratic discriminant analysis PCA-QDA), AD individuals were correctly identified with $92.8 \%$ accuracy, $87.5 \%$ sensitivity and $96.1 \%$ specificity. Our results show the potential of NIR spectroscopy as a simple and costeffective diagnostic tool for AD. Robust and early diagnosis may be a first step towards tackling this disease by allowing timely intervention. 


\section{Introduction}

Alzheimer's disease (AD), being responsible for $60-80 \%$ of the cases, constitutes the most common type of dementia. A risk factor for the development of $\mathrm{AD}$ is increasing age, which, in combination with the progressive increase in the number of elderly people, is expected to lead to $\sim 135$ million affected individuals worldwide by $2050{ }^{1}$. Apart from the detrimental impact of this disorder on patients, their families and the society, the economic burden should also be considered; the worldwide cost had been estimated to become a US\$ trillion dollar disease in $2018^{2}$. Furthermore, AD is definitively diagnosed only after a postmortem brain biopsy. It is therefore more than evident that effective means to diagnose AD accurately and at an early-stage is crucial in order to intervene with therapeutic strategies and recruit patients to clinical trials.

Infrared (IR) spectroscopy has advanced significantly over the last decades, specifically in the field of biomedical investigation ${ }^{3,4}$. By exploiting the vibrational movements of the chemical bonds within a sample after excitation, IR spectroscopy can provide quantitative and qualitative information about a sample. Technological advancements have also simplified the previously expensive and complicated instrumentation, thus facilitating the wider-use of these systems. In this study, near-IR (NIR) spectroscopy was employed to study the region of the electromagnetic spectrum ranging between $\sim 750-2500 \mathrm{~nm}$. The most prominent bands in the NIR include overtones and combinations of fundamental vibrations of $-\mathrm{CH},-\mathrm{NH},-\mathrm{OH}$ groups 5. It has been previously shown that NIR spectroscopy holds promise for biomedical applications ${ }^{6}$, including the study of human skin (skin carcinomas, atopy and leprosy) ${ }^{7}$, diabetes ${ }^{8}$, breast and colorectal cancers ${ }^{9,}{ }^{10}$, Alzheimer's disease ${ }^{11}$ and chronic fatigue syndrome ${ }^{12}$.

Spectroscopic techniques have been previously employed by independent research groups for the investigation of neurodegenerative disorders, either by analysis of brain biopsies 
or biofluids, such as cerebrospinal fluid (CSF) and blood samples ${ }^{13-17}$. The objective of the current study was to detect AD using a minimally-invasive, but at the same time rapid and inexpensive, blood test. Our aim was to use a large number of individuals and add further evidence, to the current literature, about the diagnostic capabilities of spectroscopy as a diagnostic tool.

The use of a suitable substrate in spectroscopy is also of major importance as it could distort the resultant spectral information and lead to falsified conclusions; for this reason, numerous studies have previously used costly and/or fragile substrates, such as calcium/barium fluoride or gold substrates, to avoid signal interference ${ }^{18-22}$. At the same time, however, the substrate of choice should be relatively inexpensive in order to be welcomed to a clinical setting. Therefore, a secondary aim of this study was to investigate whether the signal from the commonly-used and inexpensive low-E glass slide ${ }^{23,24}$ could be removed from the samples' spectra without affecting the diagnostic result.

\section{Materials and Methods}

\section{Patient cohort and sample collection}

Our cohort included 111 patients with AD and 173 individuals with no symptoms of $\mathrm{AD}$, who were designated as healthy controls (HC). The latter group mainly consisted of close relatives (e.g., spouses) escorting the patients at the time of examination. More information about the age and gender of the participants is provided in Table 1.

All participants were recruited at Salford Royal Hospital (Salford, UK) with informed consent obtained prior to enrolment in accordance with Local Ethical Approval (05/Q1405/24 conferred by North West 10 Research Ethics Committee Greater Manchester North). Blood samples were collected in EDTA tubes following standard operating procedures. To acquire the plasma, whole blood was centrifuged for $10 \mathrm{~min}$ at $2000 \mathrm{rpm}, 4^{\circ} \mathrm{C}$ and the supernatant was 
collected in new microtubes. Plasma samples were aliquoted and kept at $-80^{\circ} \mathrm{C}$ until needed for the spectroscopic analysis. Samples were thoroughly thawed before depositing $50 \mu \mathrm{L}$ onto IRreflective glass slides (MirrIR Low-E slides, Kevley Technologies, USA) and left to dry overnight at room temperature.

\section{NIR spectroscopy}

Spectra were acquired using an ARCoptix FT-NIR Rocket spectrometer (Arcoptix S.A., Switzerland) in the range of 900 to $2600 \mathrm{~nm}$. Samples were interrogated using the transmission mode with 10 point spectra collected per sample (resolution of $8 \mathrm{~cm}^{-1}$ ). Each sample spectrum was subtracted by a low-E slide background spectrum in order to eliminate the signal resulting from the slide.

\section{Pre-processing and computational analysis}

Data pre-processing and multivariate classification models were built using MATLAB R2014b software (MathWorks Inc., USA) with PLS Toolbox version 7.9.3 (Eigenvector Research Inc., USA) and lab-made routines. The 10 spectra collected per sample were initially averaged, and the following pre-processing steps were applied to the dataset: truncation at the biofingerprint region (1850-2150 nm) (highlighted in Fig. 1a), Savitzky-Golay (SG) smoothing to remove unwanted noise from the spectra (window $=15$ points, $2^{\text {nd }}$ order polynomial function), extended multiplicative signal correction (EMSC) to correct for light scattering and automatic weighted least squares baseline correction to remove baseline absorptions. The spectra were divided into training (70\%) and test (30\%) sets using the Kennard-Stone (KS) sample selection algorithm ${ }^{25}$. The training set was used for construction of the classification models, whereas the test set was only used for final model evaluation.

Classification was performed using principal component analysis with quadratic discriminant analysis (PCA-QDA). PCA-QDA model is based on a PCA decomposition 
followed by a Mahalanobis distance calculation. PCA reduces the original dataset into a few number of principal components (PCs) accounting for the majority of the variance across the spectra. As a result, a scores and a loading array are generated for each PC representing the variance on the sample and variable (e.g., wavelength) directions, respectively ${ }^{26}$. PCA also solves problems with ill-conditioned data (data matrix with large condition number) by reducing redundant information across the data and solving collinearity problems. For this reason, PCA is commonly employed prior to discriminant analysis, with the PCA scores used as input variables for the QDA algorithm.

As aforementioned, QDA is a classification algorithm based on a Mahalanobis distance calculation. QDA assumes classes having different variance structures, calculating an individual variance-covariance matrix for each class ${ }^{27}$. This improves the classification capacity of QDA in comparison to linear methods (e.g., linear discriminant analysis - LDA) when classes with different variances are being analysed, which occurs often in complex datasets. The QDA classification scores were calculated in a non-Bayesian form in order to reduce the degree of overfitting, as follows ${ }^{28}$ :

$Q_{i k}=\left(\mathbf{x}_{i}-\overline{\mathbf{x}}_{k}\right)^{\mathrm{T}} \mathbf{C}_{k}^{-1}\left(\mathbf{x}_{i}-\overline{\mathbf{x}}_{k}\right)$

where $Q_{i k}$ is the QDA classification score for sample $i$ of class $k$; $\mathbf{x}_{i}$ is the vector containing the classification variables for sample $i$ (i.e., PCA scores); $\overline{\mathbf{x}}_{k}$ is the mean vector for class $k$; $\mathbf{C}_{k}$ is the variance-covariance matrix of class $k$; and $\mathrm{T}$ represents the transpose matrix.

Outliers were identified using a Hotelling $\mathrm{T}^{2}$ versus $\mathrm{Q}$ residual test ${ }^{29}$. This test enables someone to create a chart containing the Hotelling $\mathrm{T}^{2}$ values in the $\mathrm{x}$-axis and the $\mathrm{Q}$ residuals in the $\mathrm{y}$ axis, where all samples far from the origin $[0,0]$ are considered to be outliers. The Hotelling $\mathrm{T}^{2}$ values represent the sum of the normalised PCA scores, which is the distance from the multivariate mean to the projection of the sample onto the PCs; and the Q residuals are the sum 
of squares of each sample in the error matrix, which are the residuals between the sample and its projection via PCA.

\section{Model validation}

Validation was performed on a patient basis, meaning that each sample represents a different patient rather than an individual spectrum. The models were validated using quality parameters including accuracy (total number of samples correctly classified considering true and false negatives), sensitivity (proportion of positives correctly identified), specificity (proportion of negatives correctly identified), positive predictive value (proportion of test positives which are true positives) and negative predictive value (proportion of test negatives which are true negatives) (Table S1) ${ }^{30}$.

In addition, receiver operating characteristics (ROC) curve was generated using easyROC version 1.3 (http://www.biosoft.hacettepe.edu.tr/easyROC/) ${ }^{31}$, where area under the curve (AUC) value was calculated as a general indicator of how well the model distinguished between the classes.

\section{Results}

In total, we acquired 1110 NIR spectra from AD patients $(n=111)$ and 1730 spectra from HC volunteers $(n=173)$. The absorption due to the low-E slide signal was subtracted from the samples' signal in order to reduce glass interference (Figure S1). The average raw and preprocessed spectra (truncation at 1850-2150 nm, SG smoothing, EMSC and baseline correction) for each class are depicted in Figure 1. Seven outliers (three due to AD and four due to HC samples) were detected using a Hotelling $\mathrm{T}^{2}$ versus $\mathrm{Q}$ residual test (Figure $\mathrm{S} 2$ ). These samples were removed from the classification model. In total, 194 samples were used in the training set (118 HC, $76 \mathrm{AD})$ and 83 samples in the test set (51 HC, $32 \mathrm{AD})$, defined by the KS algorithm. After pre-processing, slight visual differences are evident between $\mathrm{HC}$ and AD patients (Figure 
For classification, the PCA-QDA algorithm was applied using 2 PCs $(67.24 \%$ cumulative explained variance). PCA scores and loadings are depicted in Figure $2 \mathrm{a}$ and $2 \mathrm{~b}$, respectively. The scores profile on the two PCs were superposed for HC and AD samples, with no clear separation observed between the classes. The loadings profiles (Figure 2b) indicated greater differences close to regions corresponding to a combination of $\mathrm{O}-\mathrm{H}$ stretch/C-O stretch second overtone $(\sim 1860 \mathrm{~nm})$; second overtone $\mathrm{C}=\mathrm{O}$ stretching $(\mathrm{H}$-bonded) in peptides $(1908$ $\mathrm{nm}$ ); and a combination of bands consisting of $\mathrm{N}-\mathrm{H}$ bend second overtone, $\mathrm{C}-\mathrm{H}$ stretch/C $=\mathrm{O}$ stretch, $\mathrm{C}=\mathrm{O}$ stretch/N-H in-plane bend/C-N stretching in proteins $(2100 \mathrm{~nm}, 2111 \mathrm{~nm}, 2150$ $\mathrm{nm})^{32-34}$. These bands correspond to the most important spectral features used by the QDA classifier in PCA-QDA. The PCA-QDA model distinguished between AD and HC individuals with $92.8 \%$ accuracy, $87.5 \%$ sensitivity and $96.1 \%$ specificity (Table 2 ). The ROC curve and AUC value for PCA-QDA are shown in Figure 3. The AUC value (0.928) is close to the maximum of 1 , indicating its excellent predictive response.

\section{Discussion}

With improved life conditions and health care, increased longevity has resulted into a greater number of elderly people and, thus, many cases of demented individuals worldwide.

Numerous research groups have devoted substantial resources and co-ordinated their efforts to study dementias and provide an accurate diagnosis. For instance, the most studied biomarkers for $\mathrm{AD}$ are amyloid- $\beta(\mathrm{A} \beta)$ and tau protein (phosphorylated-tau and total-tau) in CSF.

197 Collection of CSF, however, is an invasive procedure, rendering routine testing difficult. The understanding that the blood-brain barrier (BBB) is a semipermeable membrane, allowing the secretion of biological molecules between brain and peripheral blood, as well as the fact that 
$500 \mathrm{~mL}$ CSF is daily absorbed into the bloodstream, has led to the characterization of blood as an "information-rich" sample ${ }^{35}$.

Blood biomarkers indicative of disease constitute a developing field with great promise in the area of neurodegenerative disorders. A great number of new, blood-based molecular tests have emerged over the years, suggesting different biological markers for the detection of $\mathrm{AD}$ and other dementias ${ }^{35-41}$. Even though the diagnostic capability of the above-mentioned tests is satisfactory, the high cost and laborious experimental work of these methods are great disadvantages for the development of a clinical test.

In contrast to conventional molecular techniques, spectroscopic tests allow costeffective and rapid results. Previous studies using the mid-IR region for the diagnosis of AD have achieved comparable diagnostic results with the current NIR study. For instance, using ATR-FTIR in the mid-IR region, Paraskevaidi et al. achieved $86 \%$ sensitivity and specificity for individuals who carried one or two alleles of apolipoprotein e4 (APOE ع 4$)^{42}$; Carmona et al. used the mid-IR (as well as Raman spectroscopy) to differentiate between healthy elderly and demented patients with a sensitivity of $89 \%$ and specificity of $92 \%{ }^{14}$; Peuchant et al. also employed mid-IR spectroscopy and achieved $98.4 \%$ diagnostic accuracy ${ }^{43}$. Other preliminary studies, have also successfully applied spectroscopic approaches (IR or Raman spectroscopy) for the diagnosis of AD or other types of dementia ${ }^{15,44,45}$; however, the small number of samples in these studies was a limitation, preventing more general conclusions. According to the NIR results of the present study, most of the differences between healthy and demented individuals seem to be related mainly to protein bands. Some of the well-known characteristics of $\mathrm{AD}$ include the built-up of $\mathrm{A} \beta$ plaques and neurofibrillary tangles (primarily consisting of tau protein) in the brain, and therefore we can speculate that the observed changes in the NIR region may be attributed to such protein changes. 

spectroscopy in the transmission mode. The PCA-QDA classification model presented $92.8 \%$ accuracy, $87.5 \%$ sensitivity and $96.7 \%$ specificity which are comparable, and even superior, to current conventional diagnostic biomarkers. Using NIR spectroscopy, also decreases the instrumental cost substantially, as instrumentation is much cheaper than other IR or Raman systems and it can be easily translated to portable systems. Our results, coming from a large cohort, add to the current literature by validating previous spectroscopic work, thus taking spectroscopy one step forward towards clinical implementation. Indeed, repetition and validation in independent research groups is of crucial importance for every new biomarker or diagnostic test prior to clinical trials. Herein, we have also shown that after appropriate spectral pre-processing, the low-E signal can be subtracted from the spectra, therefore allowing direct comparison of the sample information without interference from the slide. It should be noted here that the patient cohort in this study was already diagnosed with the disease, therefore the potential of blood-based NIR spectroscopy for pre-symptomatic detection remains to be further explored. Nevertheless, we are optimistic as previous spectroscopy studies have demonstrated segregation between early-stage/mild AD and healthy controls ${ }^{15,44,46}$, but a larger number of early-stage patients is still required.

To conclude, this study detected a blood signature for AD, showing great promise in 242 the accurate, simple and minimally-invasive diagnosis of the disease. Our main objective in the current study was to show whether NIR spectroscopy, in the transmission mode, could provide satisfactory diagnostic performance after removal of the substrate's signal. Future studies should focus on the recruitment of more participants, including asymptomatic individuals or patients with mild cognitive impairment (MCI). This would be the next big step 247 in this field, as accurate identification of MCI individuals would allow immediate management 

and recruitment into clinical trials; the latter may also prove crucial for the development of new 249 therapeutic strategies.

\section{Acknowledgments}

251 MP acknowledges Rosemere Cancer Foundation for funding. CLMM would like to thank

252 CAPES-Brazil (Doutorado Pleno no Exterior, grant 88881.128982/2016-01) for financial

253 support. KMGL would like to thank CNPq-Brazil (Bolsa de Produtividade, grant 303733/2017-

254 9) for financial support.

255

256

257 
258 Tables

259

260 Table 1: Patient characteristics

\begin{tabular}{|c|c|c|}
\hline & Alzheimer's disease & Healthy control \\
\hline \multicolumn{3}{|c|}{ Number of cases } \\
\hline & 111 & 173 \\
\hline \multicolumn{3}{|l|}{ Age } \\
\hline$<65$ & $60 / 111$ & $90 / 173$ \\
\hline$\geq 65$ & $51 / 111$ & $79 / 173$ \\
\hline Unknown & - & $4 / 173$ \\
\hline \multicolumn{3}{|l|}{ Gender } \\
\hline Female & $50 / 111$ & $103 / 173$ \\
\hline Male & $61 / 111$ & $68 / 173$ \\
\hline Unknown & - & $2 / 173$ \\
\hline
\end{tabular}

261

262

263

264

265

266

267

268

269

270 
271 Table 2: Quality parameters for PCA-QDA model. PPV: positive predictive value, NPV:

272 negative predictive value.

\begin{tabular}{ll}
\hline Parameter & Value $(\boldsymbol{\%})$ \\
\hline Accuracy & 92.8 \\
Sensitivity & 87.5 \\
Specificity & 96.1 \\
PPV & 93.3 \\
NPV & 92.5 \\
\hline
\end{tabular}

273

274

275 


\section{$276 \quad$ Figures}

a.

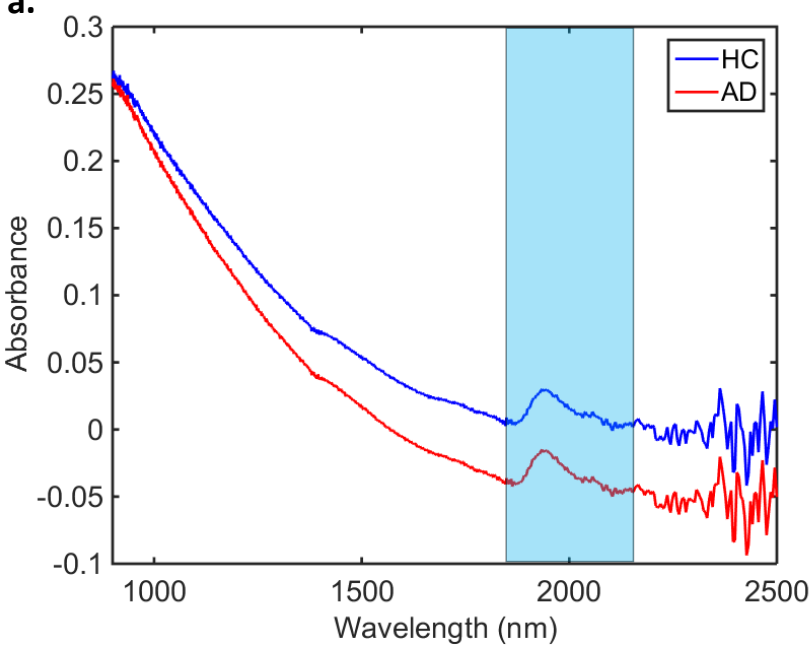

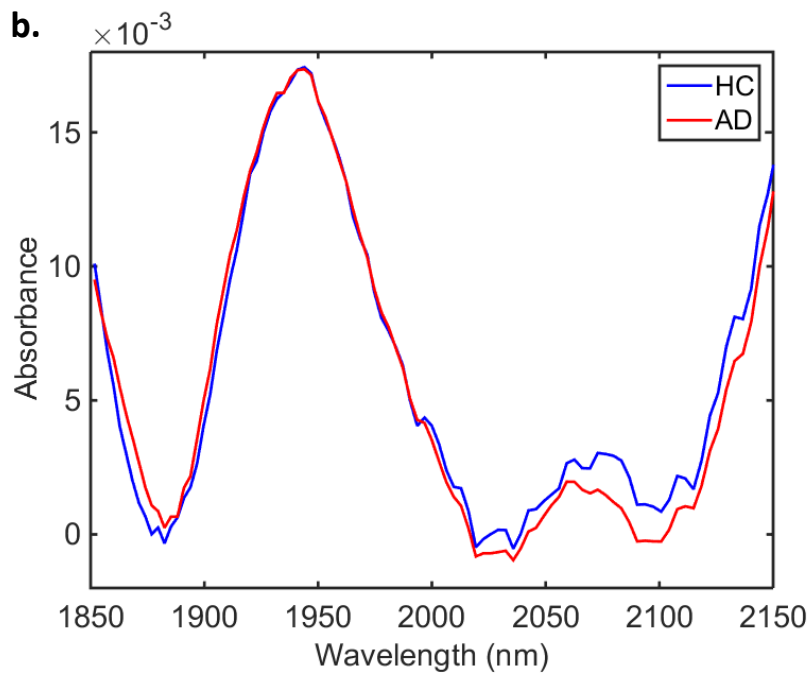

278 Figure 1. Average (a) raw and (b) pre-processed NIR spectra for healthy controls (HC) and 279 Alzheimer's disease (AD) patients. 
a.

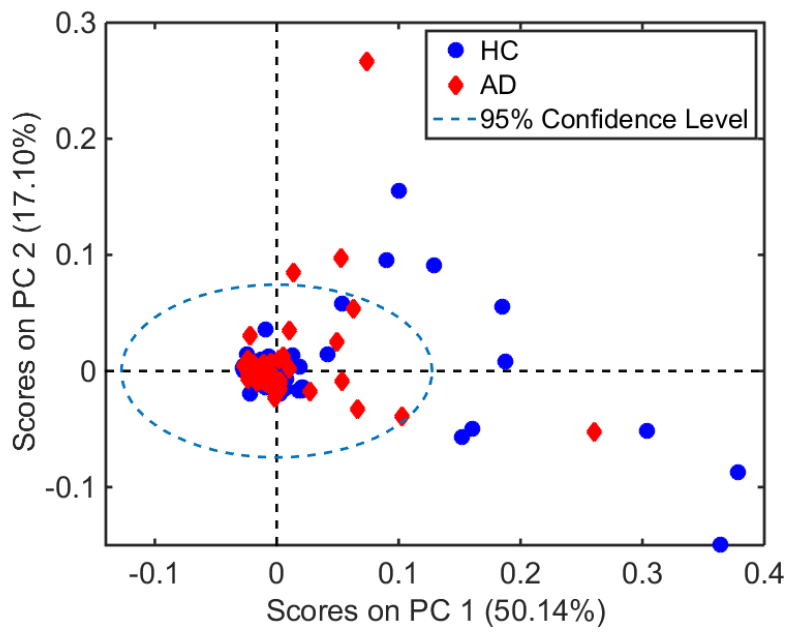

b.

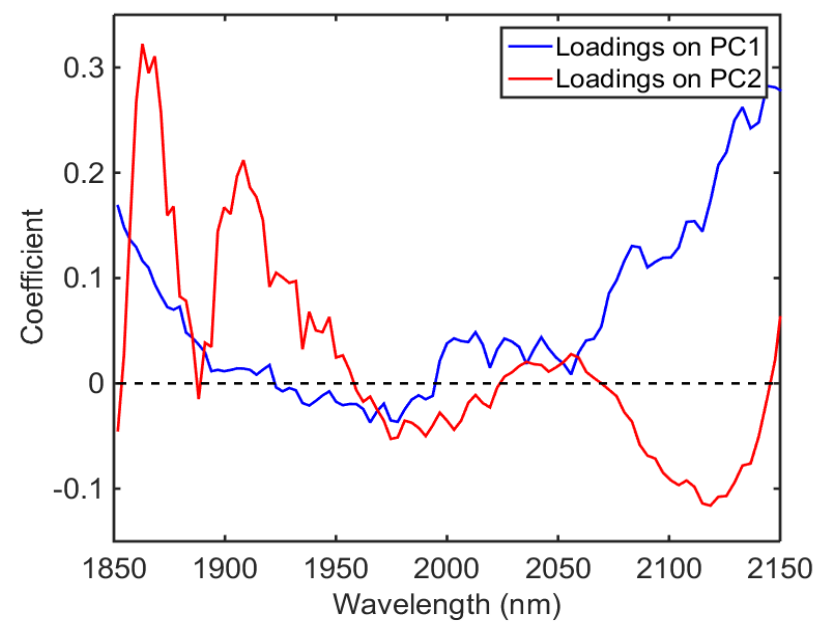

282

Figure 2. (a) PCA scores on PC1 and PC2 for healthy controls (HC) and Alzheimer's disease

284 (AD) samples (explained variance for each PC inside parenthesis); (b) PCA loadings based on 285 PC1 and PC2. 


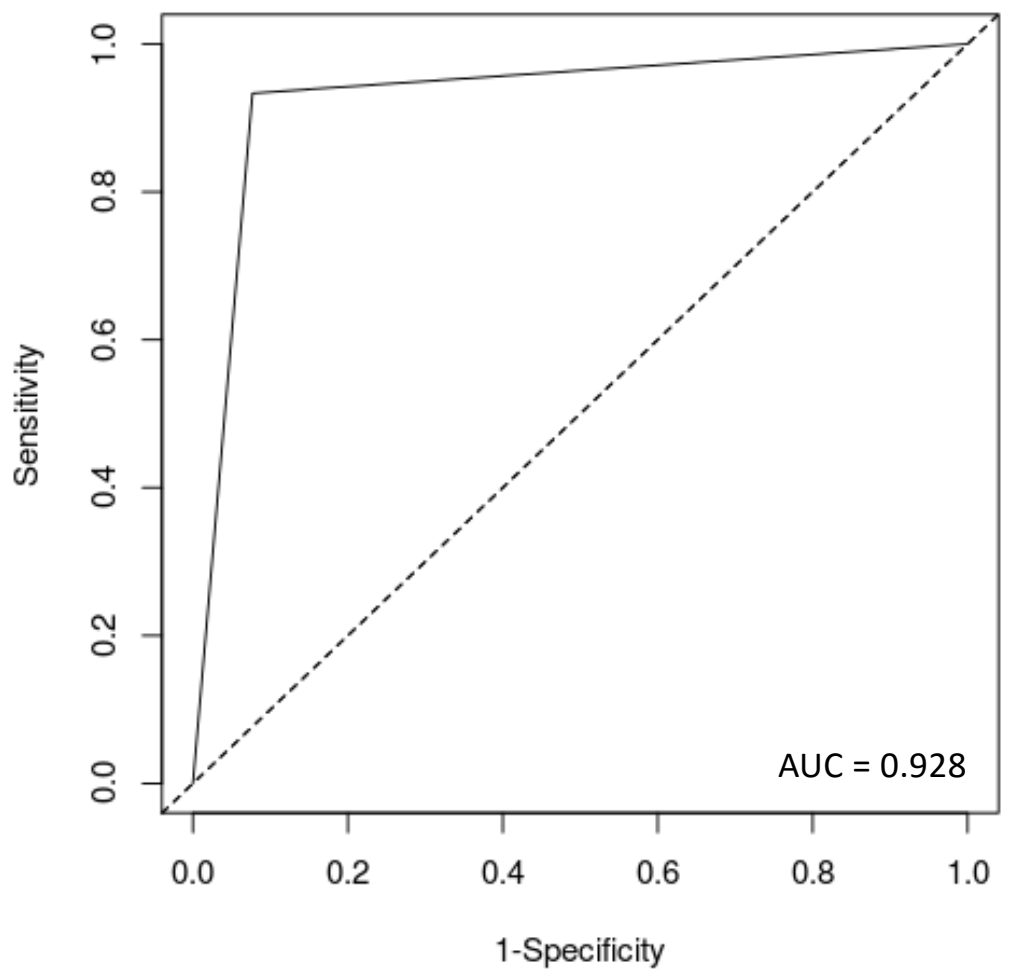

288

289 Figure 3. ROC curve for PCA-QDA model. AUC stands for area under the curve.

290

291

292

293

294

295

296

297 


\section{References}

299 1. Policy Brief for Head of Government, Alzheimer's Disease International (https://www.alz.co.uk/research/GloballmpactDementia2013.pdf).

2. P. Martin, W. Anders, G. Maëlenn, A. Gemma-Claire, W. Yu-Tzu and P. Matthew, World Alzheimer Report 2015: the global impact of dementia: an analysis of prevalence, incidence, cost and trends, Alzheimer's Disease International, 2015. (https://www.alz.co.uk/research/WorldAlzheimerReport2015.pdf).

3. L. Wang and B. Mizaikoff, Anal Bioanal Chem, 2008, 391, 1641-1654.

4. D. I. Ellis and R. Goodacre, Analyst, 2006, 131, 875-885.

5. G. Reich, Adv Drug Del Rev, 2005, 57, 1109-1143.

6. A. Sakudo, Clin Chim Acta, 2016, 455, 181-188.

7. R. K. Lauridsen, H. Everland, L. F. Nielsen, S. B. Engelsen and L. Nørgaard, Skin Res Technol, 2003, 9, 137-146.

8. G. Pichler, B. Urlesberger, P. Jirak, H. Zotter, E. Reiterer, W. Müller and M. Borkenstein, Diabetes Care, 2004, 27, 1942-1946.

9. M. K. Simick, R. A. Jong, B. C. Wilson and L. D. Lilge, J Biomed Opt, 2004, 9, 794-804.

10. H. Chen, Z. Lin, L. Mo, T. Wu and C. Tan, Biomed Res Int, 2015, 2015.

11. D. H. Burns, S. Rosendahl, D. Bandilla, O. C. Maes, H. M. Chertkow and H. M. Schipper, J Alzheimers Dis, 2009, 17, 391-397.

12. A. Sakudo, H. Kuratsune, Y. H. Kato and K. Ikuta, Clin Chim Acta, 2012, 413, 1629-1632.

13. M. Paraskevaidi, P. L. Martin-Hirsch and F. L. Martin, Mol Neurodegener, 2018, 13, 20.

14. P. Carmona, M. Molina, M. Calero, F. Bermejo-Pareja, P. Martinez-Martin and A. Toledano, J Alzheimers Dis, 2013, 34, 911-920.

15. E. Ryzhikova, O. Kazakov, L. Halamkova, D. Celmins, P. Malone, E. Molho, E. A. Zimmerman and I. K. Lednev, J Biophotonics, 2015, 8, 584-596.

16. R. Michael, A. Lenferink, G. F. Vrensen, E. Gelpi, R. I. Barraquer and C. Otto, Sci Rep, 2017, 7, 15603.

17. M. Griebe, M. Daffertshofer, M. Stroick, M. Syren, P. Ahmad-Nejad, M. Neumaier, J. Backhaus, M. G. Hennerici and M. Fatar, Neurosci Lett, 2007, 420, 29-33.

18. M. Grimbergen, C. van Swol, R. van Moorselaar, J. Uff, A. Mahadevan-Jansen and N. Stone, J Photochem Photobiol B: Biol, 2009, 95, 170-176.

19. B. W. De Jong, T. C. Bakker Schut, K. Maquelin, T. van der Kwast, C. H. Bangma, D.-J. Kok and G. J. Puppels, Anal Chem, 2006, 78, 7761-7769.

20. L. Mikoliunaite, R. D. Rodriguez, E. Sheremet, V. Kolchuzhin, J. Mehner, A. Ramanavicius and D. R. Zahn, Sci Rep, 2015, 5, 13150.

21. J. De Meutter, K.-M. Derfoufi and E. Goormaghtigh, Biomed Spectrosc Imaging, 2016, 5, 145154.

22. M. J. Pilling, P. Bassan and P. Gardner, Analyst, 2015, 140, 2383-2392.

23. L. Cui, H. J. Butler, P. L. Martin-Hirsch and F. L. Martin, Anal Methods, 2016, 8, 481-487.

24. M. J. Baker, J. Trevisan, P. Bassan, R. Bhargava, H. J. Butler, K. M. Dorling, P. R. Fielden, S. W. Fogarty, N. J. Fullwood, K. A. Heys, C. Hughes, P. Lasch, P. L. Martin-Hirsch, B. Obinaju, G. D. Sockalingum, J. Sulé-Suso, R. J. Strong, M. J. Walsh, B. R. Wood, P. Gardner and F. L. Martin, Nat Protoc, 2014, 9, 1771-1791.

25. R. W. Kennard and L. A. Stone, Technometrics, 1969, 11, 137-148.

26. R. Bro and A. K. Smilde, Anal Methods, 2014, 6, 2812-2831.

27. C. L. Morais and K. M. Lima, J Braz Chem Soc, 2017, 31.

28. S. J. Dixon and R. G. Brereton, Chemom Intellig Lab Syst, 2009, 95, 1-17.

29. J. Kuligowski, G. Quintás, C. Herwig and B. Lendl, Talanta, 2012, 99, 566-573.

30. C. L. Morais and K. M. Lima, Chemom Intellig Lab Syst, 2017.

31. D. Goksuluk, S. Korkmaz, G. Zararsiz and A. E. Karaagaoglu, R Journal, 2016, 8, e30. 
349 33. S. Türker-Kaya and C. W. Huck, Molecules, 2017, 22, 168.

350 34. M. Manley, Chem Soc Rev, 2014, 43, 8200-8214.

35. A. Hye, S. Lynham, M. Thambisetty, M. Causevic, J. Campbell, H. L. Byers, C. Hooper, F. Rijsdijk, S. J. Tabrizi, S. Banner, C. E. Shaw, C. Foy, M. Poppe, N. Archer, G. Hamilton, J. Powell, R. G. Brown, P. Sham, M. Ward and S. Lovestone, Brain, 2006, 129, 3042-3050.

36. S. Ray, M. Britschgi, C. Herbert, Y. Takeda-Uchimura, A. Boxer, K. Blennow, L. F. Friedman, D. R. Galasko, M. Jutel and A. Karydas, Nat Med, 2007, 13, 1359.

37. B. Olsson, R. Lautner, U. Andreasson, A. Öhrfelt, E. Portelius, M. Bjerke, M. Hölttä, C. Rosén, C. Olsson and G. Strobel, Lancet Neurol, 2016, 15, 673-684.

38. N. Mattsson, U. Andreasson, H. Zetterberg, K. Blennow and I. for the Alzheimer's Disease Neuroimaging, JAMA Neurol, 2017, 74, 557-566.

39. N. Mattsson, H. Zetterberg, S. Janelidze, P. S. Insel, U. Andreasson and E. Stomrud, Neurology, 2016, 87.

40. M. Mapstone, A. K. Cheema, M. S. Fiandaca, X. Zhong, T. R. Mhyre, L. H. MacArthur, W. J. Hall, S. G. Fisher, D. R. Peterson, J. M. Haley, M. D. Nazar, S. A. Rich, D. J. Berlau, C. B. Peltz, M. T. Tan, C. H. Kawas and H. J. Federoff, Nat Med, 2014, 20, 415-418.

41. A. Nakamura, N. Kaneko, V. L. Villemagne, T. Kato, J. Doecke, V. Doré, C. Fowler, Q.-X. Li, R. Martins and C. Rowe, Nature, 2018, 554, 249.

42. M. Paraskevaidi, C. L. Morais, K. M. Lima, J. S. Snowden, J. A. Saxon, A. M. Richardson, M. Jones, D. M. Mann, D. Allsop and P. L. Martin-Hirsch, Proc Natl Acad Sci USA, 2017, 201701517.

43. E. Peuchant, S. Richard-Harston, I. Bourdel-Marchasson, J. F. Dartigues, L. Letenneur, P. Barberger-Gateau, S. Arnaud-Dabernat and J. Y. Daniel, Transl Res, 2008, 152, 103-112.

44. S. Mordechai, E. Shufan, B. P. Katz and A. Salman, Analyst, 2017, 142, 1276-1284.

45. P. Carmona, M. Molina, E. López-Tobar and A. Toledano, Anal Bioanal Chem, 2015, 407, 77477756.

46. M. Paraskevaidi, C. L. Morais, D. E. Halliwell, D. M. Mann, D. Allsop, P. L. Martin-Hirsch and F. L. Martin, ACS Chem Neurosci, 2018. 